Revista Triângulo

ISSN 2175-1609

\title{
NOVOS LETRAMENTOS, MULTILETRAMENTOS E PROTÓtIPOS DE ENSINO: PRODUÇÃO E ANÁLISE DE UM LIVRO DIGITAL INTERATIVO
}

\author{
NEW LITERACIES, MULTILITERACIES AND TEACHINT PROTOTYPE: PRODUCTION AND \\ ANALYSIS OF A INTERACTIVE DIGITAL BOOK
}

\author{
NUEVOS LETRAMIENTOS, MULTILETRAMIENTOS Y PROTÓTIPOS DE ENSINO: \\ PRODUCCIÓN Y ANÁLISIS DE UN LIBRO DIGITAL INTERACTIVO
}

\author{
Jezreel Gabriel Lopes \\ Universidade Estadual de Campinas (Unicamp) \\ E-mail: gabriellopes17@hotmail.com
}

\begin{abstract}
RESUMO
O presente artigo tem por objetivo descrever e analisar as potencialidades de ensino de um material didático digital interativo (MDDI) para tablets, elaborado com base no conceito de protótipos de ensino (ROJO, 2017a; 2017b) e voltado para o ensino de produção e interpretação textual no Ensino Médio. Além disso, pretende-se analisar as propiciações desse tipo de material em sala de aula ao lidar com as especificidades da comunicação no contexto contemporâneo, no qual, em razão das novas tecnologias da comunicação e da informação, observase a emergência de novas práticas sociais e, consequentemente, de novas formas de letramento.
\end{abstract}

PALAVRAS-CHAVE: Protótipos de ensino. Novos letramentos. Multiletramentos.

\section{ABSTRACT}

The article aims to describe briefly an interactive digital teaching material for tablets elaborated based on the notion of teaching prototypes (ROJO, 2017a; 2017b) and focused on teaching reading and writing Portuguese language at High School. In addition, we intend to analyze the potential of this type of material at classrooms to deal with the specificities of communication in the contemporary context, focusing the new communication and information technologies, new social practices and new forms of literacy.

KEYWORDS: Teaching prototypes. New literacies. Multiliteracies.

\section{RESUMEN}

El presente artículo tiene por objetivo describir y analizar las potencialidades de enseñanza de un material didáctico digital interactiva (MDDI) para tabletas, elaborado con base en el concepto de prototipos de enseñanza (ROJO, 2017a, 2017b) y orientado a la enseñanza de producción e interpretación en la enseñanza media. Además, se pretende analizar las propiciaciones de ese tipo de material en el aula al tratar con las especificidades de la comunicación en el contexto contemporáneo, en el cual, en razón de las nuevas tecnologías de la comunicación y de la información, se observa la emergencia de nuevas prácticas sociales y, por consiguiente, de nuevas formas de letra.

PALABRAS-CLAVE: Prototipos de enseñanza. Nuevos letramientos. multiletramientos

\section{INTRODUÇÃO}

1.1 Letramentos e sua abordagem sociocultural 
Revista Triângulo

ISSN 2175-1609

Para que se entendam as demandas de ensino às quais o material didático elaborado para esta pesquisa visa a suprir, é preciso, primeiramente, discorrer sobre a concepção de letramentos e, em seguida, discutir duas outras concepções com as quais dialoga: a de multiletramentos e a de novos letramentos.

Lankshear e Knobel (2007), antes de apresentarem definição para o que chamam de novos letramentos, buscam os fundamentos do conceito de letramento tendo por base os Novos Estudos do Letramento (New Literacy Studies), liderados por Street (1984; 1995). Street, fundador da corrente teórica Novos Estudos do Letramento (NEL ou NLS, em inglês), propõe uma visão etnográfica dos estudos do letramento como prática social de poder e de empoderamento. Assim, segundo o autor, letramento deve ser definido sob uma perspectiva sociocultural, a partir da qual as práticas de leitura e de escrita são compreendidas como parte integral de um contexto social, cultural, político e econômico.

Para Street (2003, p. 77), os NEL

representam uma nova tradição ao abordar a natureza do letramento, na qual há menos foco na aquisição de habilidades, como é recorrente nas abordagens tradicionais, e ênfase no que significa pensar em letramento como prática social (Street, 1985). Isso acarreta o reconhecimento de múltiplos letramentos, que variam de acordo com o tempo e o espaço, mas também se confrontam às relações de poder. NEL, portanto, não toma nada como óbvio com respeito a letramento e às práticas sociais com as quais está associado, problematizando o que é considerado letramento num dado tempo e espaço e questionando quais letramentos são dominantes e quais são marginalizados ou de resistência. (tradução nossa)

Lankshear e Knobel explicam que os novos estudos do letramento têm como cerne a relação entre a prática humana e a produção, distribuição, troca, refinamento, negociação e contestação de significados. Os autores ainda afirmam não ser possível haver prática sem que haja significado, assim como não há significado fora da prática. Diante disso, não há leitura ou escrita significantes (meaningful sense) desassociadas de práticas sociais (LANKSHEAR; KNOBEL, 2007, p. 2).

Se vemos letramento como "simplesmente ler e escrever" - mesmo que no sentido de codificação e decodificação, como uma ferramenta, um conjunto de habilidades ou o mesmo como algum tipo de processo psicológico nós não podemos compreender nossa experiência de letramento. Ler (ou escrever) é sempre ler algo em particular com entendimento. Diferentes tipos de texto requerem diferentes backgrounds e diferentes habilidades. Além disso, alguns textos podem ser lidos (lidos de forma plena) de formas 
diferentes, a partir das diferentes práticas nas quais esses textos ocorrem. (LANKSHEAR; KNOBEL, 2007, p. 2, tradução nossa) ${ }^{2}$

Os autores exemplificam a asserção acima ao afirmarem que textos bíblicos podem ser lidos de maneiras muito distintas por pessoas imersas em contextos distintos. Ou seja, um fundamentalista cristão não faria a mesma leitura ou usos da Bíblia que faria um padre adepto da teologia da libertação. Isso ocorre, de acordo com Lankshear e Knobel, pois aprender a ler e a escrever tipos particulares de texto pressupõe imersão em práticas sociais em que os participantes não se limitem a ler tais textos, mas falam sobre eles de determinada forma, mantêm determinadas atitudes e valores diante deles e interagem socialmente sobre esses textos.

Assim, os pesquisadores concluem que é impossível abstrair ou descontextualizar pequenas partes de letramento (literacy bits) das amplas práticas sociais às quais elas se relacionam e ainda manter seus significados. Diante disso, não é possível caracterizar letramento como um único fenômeno. Em vez disso, observa-se que há tantos tipos de letramento quanto há práticas sociais, leitores e concepções de leitura e escrita.

\section{REFERENCIAL TEÓRICO}

\subsection{Novos letramentos}

Diante da concepção de letramentos em sua abordagem sociocultural, Lankshear e Knobel (2007) afirmam que os novos letramentos - isto é, aqueles que decorrem do funcionamento das tecnologias digitais da informação e comunicação (TDIC) - abrangem o que denominam novas tecnologias e um novo ethos $^{3}$ (p. 7, tradução nossa) ${ }^{4}$.

Os autores distinguem também os novos letramentos em duas categorias: os casos paradigmáticos de novos letramentos (paradigm cases of new literacies) e os casos periféricos de novos letramentos (peripheral cases of new literacies). Lankshear e Knobel afirmam que seu foco de estudo reside na primeira categoria, isto é, os casos paradigmáticos de novos letramentos. A distinção entre as categorias levantadas é explicada por eles da seguinte forma:

Casos paradigmáticos de novos letramentos têm relação com novas tecnologias digitais (digitalidade) e situam-se em um novo ethos. Casos periféricos de novos letramentos situam-se num novo ethos, mas não têm relação com as novas tecnologias. Em outras palavras, se um letramento não se situa em novo ethos, não é possível considerá-lo como novo letramento, 
mesmo que ele se relacione às tecnologias digitais. (LANKSHEAR; KNOBEL, 2007, p. 7, tradução nossa) ${ }^{5}$

Segundo os pesquisadores, essa dupla condição, situar-se em um novo ethos e relacionar-se a novas tecnologias (new technical stuff), é necessário, pois é possível se utilizar tecnologias digitais para replicar práticas tradicionais de letramento, como, por exemplo, é comumente constatado em salas de aula, nas quais se inserem computadores, lousas digitais e dispositivos móveis, mas mantêm-se os mesmos paradigmas educacionais e usos da escrita já consolidados na instituição escolar.

Para que se compreenda de forma mais clara o conceito de novos letramentos, os autores apresentam definições para new technical stuff e new ethos stuff. Segundo eles, para conceituar o que chamam de new technical stuff, é preciso considerar que há atualmente à disposição diferentes tipos de aparatos tecnológicos, como computadores, consoles de games, mp3 players, por meio dos quais se utilizam softwares com aplicabilidades diversas, como, por exemplo, produção e edição de textos, de imagens e para comunicação. Alguém com acesso a tais recursos, mesmo possuindo pouco conhecimento técnico das funcionalidades de um software, pode criar uma gama de produções (textos multimodais, animações, imagens, músicas), utilizando uma série de operações, tais como digitar, clicar, copiar, colar, arrastar, em pouco tempo e com uma ou duas ferramentas.

Para Lankshear e Knobel, um novo ethos consiste em uma nova ética, uma nova mentalidade para lidar com os discursos veiculados na sociedade contemporânea. Essa nova ética enfatiza uma maior participação das pessoas e maior colaboratividade na produção de discursos, fator que resulta na dissolução da autoria e das relações assimétricas. Além disso, dispensam-se conhecimentos técnicos altamente especializados e recursos tecnológicos caros na produção de tais discursos, fato que, há algumas décadas, não seria possível. Consequentemente, evidencia-se que, nesse novo ethos, as regras e normas são mais fluídas e menos formatadas e as hierarquias se dissolvem.

A Tabela 1 sintetiza e organiza as mentalidades apresentadas pelos autores: 
Revista Triângulo

ISSN 2175-1609

O mundo opera basicamente de acordo com princípios e lógicas físicas/materiais e industriais.

O valor varia em função da escassez

A produção é baseada num modelo industrial.

Produtos são artefatos materiais e mercadorias

Produção é baseada na infraestrutura e em unidades e centros de produção (por exemplo, uma firma ou uma companhia).

Ferramentas são, em sua maioria, ferramentas de produção.

O indivíduo é a unidade de produção, competência e inteligência.

Habilidades e autoridade estão localizadas no indivíduo e nas instituições.

O espaço é fechado e obedece a finalidades específicas.

Relações sociais marcadas pela hegemonia do livro prevalecem; uma "ordem do texto" estável.
O mundo opera, cada vez mais, de acordo com princípios e lógicas não-materiais (ou seja, ciberespaciais) e pós-industriais. O mundo é descentralizado e plano.

O valor varia em função da dispersão.

Visão pós-industrial da produção.

Produtos gerados a partir dos serviços que o requerem (customização).

Foco no processo de alavancagem e de participação não finita.

Cada vez mais, ferramentas são de mediação e tecnologias para relacionamento.

O foco é, cada vez mais, no coletivo como a unidade de produção, competência e inteligência.

Habilidades e autoridade são distribuídas e coletivas; habilidades híbridas.

O espaço é aberto, contínuo e fluido.

Relações sociais marcadas pela crescente participação das mídias digitais são cada vez mais visíveis; textos em mudança contínua.

Tabela: Comparação entre mentalidades

Lankshear e Knobel, como observado na Tabela 1, apontam para a emergência de uma nova mentalidade - mentalidade 2.0, em analogia à Web 2.0 -, enquanto a mentalidade anterior é análoga à $W e b 1.0$. O conceito de $W e b 1.0$ se relaciona ao uso da internet voltado 


\section{Revista Triângulo}

ISSN 2175-1609

para armazenamento e processamento de informações. Ou seja, nesse caso, os autores apontam, na mentalidade 1.0, para a predominância de uma lógica de comunicação unidirecional, menos colaborativa, e de consumo de informação de forma passiva, controlada por produtores de conteúdo. Já no caso da Web 2.0/mentalidade 2.0, o foco é na relação entre pessoas e instituições e na colaboratividade. Nesse contexto de Web, há diluição das fronteiras entre usuários e desenvolvedores de conteúdo, autoria distribuída e inteligência coletiva.

Ao observar as duas mentalidades expostas, nota-se que, na contemporaneidade, o mundo opera em uma lógica centrada não no material, mas sim nas relações no ciberespaço, em que serviços têm maior importância que mercadorias. Além disso, o valor se relaciona à dispersão de um conteúdo e não mais à escassez, visto que, quanto mais pessoas têm acesso a um conteúdo, ou seja, quanto mais esse se espalha, mais valorizado ele é.

Em relação às práticas de letramento, nota-se que, na mentalidade 2.0, há mudanças profundas de paradigma, nas quais a autoria individual de um texto é substituída pela produção colaborativa; raridade e ineditismo das produções cedem lugar a textos cunhados a partir de remixes ${ }^{6}$ e cuja valorização se dá por sua ampla disseminação, a partir de reblogagens e compartilhamentos, e por sua apreciação por meio de comentários, "curtidas" em redes sociais e apropriação desses textos para criação de novas produções. Dentro dessa lógica, desse novo ethos, evidencia-se que a circulação dos textos não mais é controlada por casas publicadoras, editores, livrarias e direitos de autor, mas segue a lógica da ampla disseminação, autoria coletiva e reelaboração.

\subsection{Multiletramentos}

A emergência das novas tecnologias da informação e comunicação na sociedade contemporânea proporcionou, como vimos, mudanças significativas nas práticas de letramento e nas relações entre os atores envolvidos em tais práticas. Diante desse contexto de evolução tecnológica e de estabelecimento de novas relações e práticas sociais, em meados da década de noventa, um grupo de especialistas em linguagem e educação, conhecido como Grupo de Nova Londres $(\mathrm{GNL})^{7}$, articulou o conceito de multiletramentos, a partir da observação e interpretação das mudanças vigentes no mundo naquela época e ainda hoje. $\mathrm{O}$ termo multiletramentos foi cunhado de forma a ser capaz de designar dois tipos de 
multiplicidade crescentes na sociedade, a multissemiose dos textos em circulação e a multiplicidade de culturas em contato no mundo globalizado.

Sobre a primeira das multiplicidades discutidas pelo Grupo de Nova Londres, a multissemiose ou multimodalidade, pode-se dizer que a contemporaneidade apresenta um contexto comunicacional no qual a informação, por meio de variadas mídias ${ }^{8}$, materializa-se em diversas modalidades de linguagem ${ }^{9}$ que se combinam entre si durante o processo comunicativo, expandindo ou limitando a significação de um determinado discurso (LEMKE, 2011).

Além da multissemiose, o conceito de multiletramentos também se relaciona à multiplicidade de culturas, expressas por diferentes linguagens e seus usos em contextos específicos. Assim, Cope e Kalantzis (2006) explicam que, central à abordagem por eles proposta, está a crescente variedade de "linguagens sociais", nomenclatura proposta por Gee (1996), em grupos de interesse ou afinidade, no âmbito profissional, nacional, étnico e subcultural. Segundo os autores, a disseminação dessas multiplicidades (culturais e de linguagens) acompanha a reestruturação do funcionamento de três âmbitos da vida humana: o do trabalho (diversidade produtiva), o da cidadania (pluralismo cívico) e o da vida social (KALANTZIS; COPE, 2006[2000]). Para Cope e Kalantzis, dessa forma, além de considerar as multiplicidades abarcadas pelos multiletramentos, uma educação linguística apropriada ao contexto contemporâneo precisa levar em conta a reestruturação desses âmbitos da vida humana e suas demandas.

No âmbito do trabalho, os autores salientam suas transformações, ao explicar que a modernidade tardia não mais se organiza de maneira fordista, ou seja, por meio da divisão do trabalho em linha de produção e da produção e consumo de massas. No pós-fordismo, necessita-se de um trabalhador multicapacitado, autônomo e flexível para adaptação a constantes mudanças. Mesmo as tradicionais e rígidas hierarquias presentes no ambiente profissional são substituídas por relações colaborativas e em moldes pedagógicos (profissionais encarregados de agir como mentores, de treinar e de ensinar).

Quanto às reestruturações no âmbito do pluralismo cívico, Cope e Kalantzis chamam a atenção para o declínio do conceito de ser cidadão sob a perspectiva nacionalista e monocultural. Assim, em vez de um Estado fundamentado em apenas uma cultura e uma língua, necessita-se de Estados capazes de negociar a diferença e de desenvolver em seus 
cidadãos a habilidade de expressar e representar identidades multifacetadas apropriadas a diferentes modos de vida, espaços cívicos e contextos de trabalho em que cidadãos se encontram (COPE; KALANTZIS, 2006 [2000], p. 271, tradução nossa) ${ }^{10}$; a ampliação dos repertórios culturais apropriados ao conjunto de contextos em que a diferença tem de ser negociada; e a capacidade de se engajarem numa política colaborativa que combina diferenças em relações de complementaridade" (COPE; KALANTZIS, 2006 [2000], p. 272, tradução nossa) ${ }^{1}$.

Por fim, com respeito ao âmbito da vida privada, as muitas culturas híbridas vivenciadas por cada um de nós na contemporaneidade geram uma consciência descentrada e fragmentada. Segundo os autores, ninguém consegue pertencer a uma única comunidade. Em vez disso, as pessoas estão inseridas em múltiplas comunidades (comunidades de trabalho, de interesse, de etnia, de identidade sexual) que se sobrepõem, constituindo, assim, relações complexas entre si. Por essa razão, Cope e Kalantzis afirmam ser necessário buscar um pluralismo integrativo, no qual a diversidade se torne a base paradoxal da coesão.

Concomitantemente a essa reestruturação dos âmbitos da vida humana, as tecnologias digitais permitiram uma nova configuração nas relações sociais, bem como das relações entre cidadãos e instituições. Segundo Cope e Kalantzis (2009), a antiga relação hierárquica Estado-cidadão (top-down) tem sido substituída por uma relação em que pessoas desempenham um papel cada vez mais ativo na sociedade, passando de meros espectadores a atores (bottom-up). Os autores explicam que, conforme a influência do Estado diminui, presenciamos a emergência de estruturas que governam a si mesmas na sociedade civil, a exemplo de certos espaços na internet. A autonomia alcançada nas últimas décadas evidencia-se também - sobretudo nas gerações mais jovens - no controle de seleção de informação que chega até nós, bem como nos canais utilizados para isso:

Eles (as novas gerações) buscam ser atores em vez de audiência, jogadores em vez de espectadores [...]. Não contentes com o rádio, essas crianças criam suas próprias playlists em seus iPods. Não contentes com a televisão tradicional, eles leem suas narrativas por DVDs e vídeos via internetstream, variando na profundidade dessa leitura (o filme, o documentário a respeito do making-of do filme) [...]. Não contentes com uma visão única da transmissão de jogos esportivos pela televisão aberta, eles escolhem seus próprios ângulos, replays e análises estatísticas na televisão interativa. (COPE; KALANTZIS, 2009, p. 173, tradução nossa) ${ }^{2}$ 
Assim, percebe-se que as pessoas deixam de ser apenas receptores de informação, ocupando, agora, um papel protagonista na busca, seleção e formatação da informação que desejam consumir. Além disso, o contexto tecnológico propicia novas práticas e dilemas advindos da cibercultura (LEMOS, 2002) e da cultura da convergência (JENKINS, 2008) como, por exemplo, as fronteiras entre vida pública e privada e os limites legais para práticas de remixagem. Tais assuntos estão no campo dos multiletramentos e novos letramentos, portanto, deveriam ser concernentes também à instituição escolar.

Embora o contexto contemporâneo tecnológico e multicultural esteja na base da definição do conceito de multiletramentos proposto pelo Grupo de Nova Londres, é um equívoco considerá-lo como sinônimo do conceito de novos letramentos proposto por Lankshear e Knobel (2007). Enquanto o primeiro constrói-se com base na multissemiose e multiculturalidade, o segundo, ainda que eventualmente acabe por abarcar esses dois aspectos, necessita das perspectivas técnicas oriundas das novas tecnologias de informação e comunicação juntamente a uma nova ética proporcionada por essas tecnologias. Assim, é possível afirmar que nem toda prática social situada nos multiletramentos é, de fato, um novo letramento. Para este artigo, consideramos importante conceituar ambos os casos, pois o material didático digital interativo e as relações estabelecidas em sala de aula mediante sua aplicação relacionam-se a essas duas concepções e sua distinção terá papel importante na análise do livro digital interativo.

\section{MATERIAIS E MÉTODOS}

3.1 Protótipos de ensino para webcurrículos

As demandas educacionais para a contemporaneidade, discutidas pelo Grupo de Nova Londres e por Lankshear e Knobel, nortearam a elaboração de um material didático digital interativo $^{3}$ para tablets que visa ao trabalho com leitura e produção de textos no Ensino Médio de escola privada. A estruturação do material em questão teve como objetivo o trabalho com novos letramentos e multiletramentos, visando a leitura e produção de textos no ensino-aprendizagem de Língua Portuguesa, com foco em gêneros. Adotamos a concepção de gêneros de discurso proposta por Bakhtin (2003[1952-53/1979]) como "tipos relativamente estáveis de enunciados", elaborados em uma esfera social, caracterizados por sua temática, estilo e construção formal, grandemente ditados pela valoração que os orienta. 


\section{Revista Triângulo}

ISSN 2175-1609

Esse material foi elaborado por meio do aplicativo iBooks Author, distribuído gratuitamente pela MacApp Store ${ }^{4}$. O aplicativo em questão permite que se idealizem livros digitais interativos multissemióticos, maximizando as possibilidades de uso de dispositivos digitais móveis como os tablets em sala de aula, além de permitir uma estruturação do material didático seguindo os parâmetros propostos para o que se concebe como protótipo de ensino.

Para Rojo (2013), um protótipo de ensino seria um "esqueleto" de SD [sequência didática] a ser "encarnado" ou preenchido pelo professor, por exemplo, um modelo didático digital de um gênero ou conjunto de gêneros, sem seus acervos ou bancos de textos, ou apenas com acervos e bancos que funcionassem como exemplos e pudessem ser substituídos no produto final.

Se o protótipo é na verdade um esqueleto, o que então o constituiria? Segundo a autora, o modelo didático do(s) gênero(s) em questão, ou parte dele: aquela parte que diz respeito às características e funcionamento do(s) gênero(s), segundo as teorias e os saberes práticos correntes, ao conjunto de princípios de ensino-aprendizagem adotados e aos possíveis objetivos de ensino a serem selecionados para compor os módulos de ensino.

Ainda de acordo com Rojo (2017a), o protótipo é um material navegável e interativo, constituído por um discurso autoral/professoral, por meio do qual seja possível conduzir os alunos a um trabalho digital aberto, investigativo e colaborativo. Ao longo do processo de ensino, o papel do professor é o de mediador. Por fim, a autora explica que os protótipos devem propiciar ao docente as possibilidades de escolha de acervos de textos e mídias alternativos ao acervo principal da proposta didática.

Contudo, mais que apenas disponibilizar materiais voltados ao trabalho com multiletramentos e novos letramentos e inserir novas tecnologias em sala de aula, é preciso que se pense um currículo capaz de incorporar de fato esses recursos ao ensino. A fim de contribuir com a discussão acerca de um ensino estruturado de acordo com a realidade contemporânea, Almeida (2014) propõe o que denomina de Web-currículo. Segundo a pesquisadora, o Web-currículo

se desenvolve por meio das tecnologias digitais de informação e comunicação, especialmente mediado pela internet. Uma forma de trabalhálo é informatizar o ensino ao colocar o material didático na rede. Mas o web-currículo vai além disso: ele implica a incorporação das principais características desse meio digital no desenvolvimento do currículo. Isto é, implica apropriar-se dessas tecnologias em prol da interação, do trabalho colaborativo e do protagonismo entre todas as pessoas para o 


\section{Revista Triângulo}

ISSN 2175-1609

desenvolvimento do currículo. É uma integração entre o que está no documento prescrito e previsto [currículo estabelecido] com uma intencionalidade de propiciar o aprendizado de conhecimentos científicos com base naquilo que o estudante já traz de sua experiência. O webcurrículo está a favor do projeto pedagógico. Não se trata mais do uso eventual da tecnologia, mas de uma forma integrada com as atividades em sala de aula. (ALMEIDA, 2014, p. 1-2)

Ainda para Almeida, desenvolver um trabalho com Web-currículos consiste, entre outros aspectos, em

usar as linguagens veiculadas pelas TDIC em atividades que propiciem aos aprendizes a fluência tecnológica para utilizar mecanismos automáticos de busca de informações; avaliar a qualidade da informação em relação à fidedignidade da fonte e à sua relevância para o tema de estudos; participar de redes dialógicas de compartilhamento de experiências e de produções sobre temas de interesse comum; entender as formas de atribuir significados sobre o mundo por pessoas de distintos contextos e culturas; criar textos e hipermídias combinando palavras, sons, imagens, animações e vídeos para representar o conhecimento; formalizar o conhecimento produzido a partir de uma reflexão sobre processos e produções; compreender o alcance global de uma informação tornada pública com a consciência e responsabilidade social de que ela está disponível para todos. (ALMEIDA, 2014, p. 22-23)

Rojo (2017a) sugere possibilidades para o que constituiria um material didático que encaminhe o processo de ensino de forma que a aprendizagem seja interativa, colaborativa e protagonista. Para isso, a autora defende o uso dos protótipos, que, segundo ela, propiciariam apoio e formação de professores em um trabalho baseado em multiletramentos e novos letramentos. Dessa forma, seu uso no ensino afastaria o processo de ensino das práticas observadas, por exemplo, nos laboratórios de informática das escolas. Neles, as "máquinas individuais, baixas bandas de conexão (quando existentes) e dispositivos instalados em linha e coluna impedem a interação" (ROJO, 2017a, p. 207). Para Rojo, ao utilizar protótipos, seria mais adequado o uso de "smartphones, tablets, netbooks ou notebooks, um ou dois por grupos [de alunos], com uma banda boa de conexão" (ROJO, 2017a, p. 207). Além disso, o professor deve dispor de "algum meio de totalização, seja um datashow, uma TV ou uma lousa digital e uma disposição espacial dos mobiliários que favoreça o trabalho coletivo [...]" (ROJO, 2017a, p. 207).

\section{ANÁLISE DOS DADOS E RESULTADOS}

4.1 Princípios de confecção do livro digital interativo (LDDI)

Com base nos conceitos de novos letramentos e de multiletramentos, elaborou-se um livro didático digital interativo (LDDI) sobre a temática Aquecimento Global, pensado no 
contexto de um web-currículo e de protótipos de ensino. Embora o material tenha sido objeto de trabalho com uma turma de Ensino Médio e o registro da experiência tenha servido para analisar a caracterização de aulas mediadas por novas tecnologias ${ }^{5}$, o foco do presente artigo recai sobre a descrição desse material didático e sobre a concepção pensada para sua implementação.

Previamente à construção do LDDI, estabeleceram-se objetivos pedagógicos a serem alcançados a partir da aplicação do material: (a) compreender o fenômeno do aquecimento global e as variáveis que o envolvem; (b) analisar por meio desse fenômeno temáticas de espectro mais amplo, tais como a neutralidade científica e o papel da mídia na divulgação científica; (c) ler, analisar, interpretar e produzir textos em gêneros escritos e multissemióticos.

Assim, tendo por base os objetivos pedagógicos elencados, o material didático foi construído de forma a contrapor discursos científicos contrastantes acerca dos consensos e controvérsias a respeito do aquecimento global, por meio de leitura e interpretação de textos em gêneros escritos e multissemióticos. Ao longo de três seções, o protótipo caracteriza o fenômeno aquecimento global e amplia a discussão para questões como o papel dos veículos de comunicação na construção do discurso científico e a influência de fatores políticos, ideológicos e econômicos nesse discurso. Por fim, o material apresenta três sugestões de prática de produção de gênero (carta do leitor, dissertação ou produção de um Tumblr ${ }^{6}$ ), embasadas na discussão realizada. Nas tabelas a seguir, encontra-se a descrição de todo o material quanto a seus objetivos, gêneros que o compõem, sistema semiótico e as modalidades de linguagem presentes.

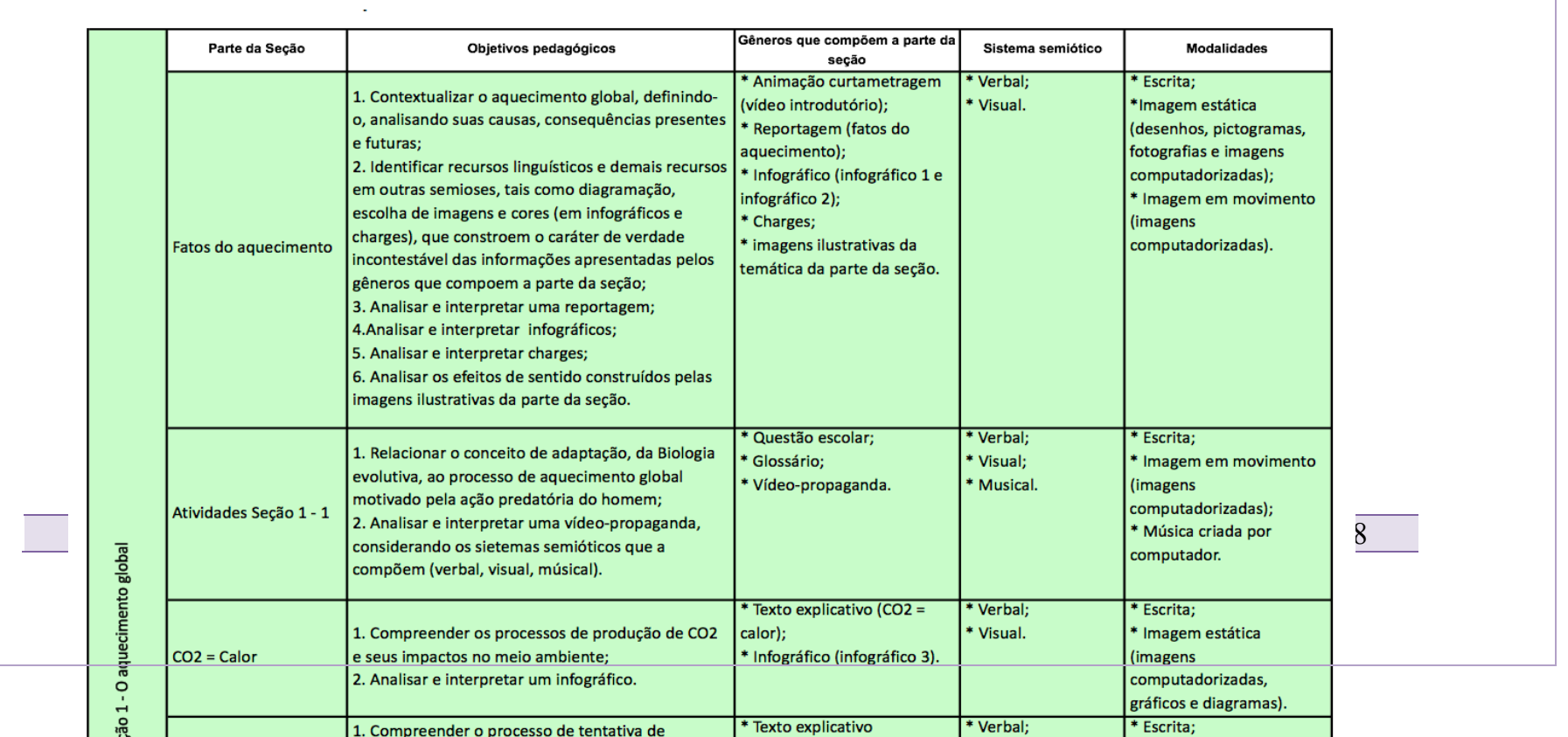


Revista Triângulo

ISSN 2175-1609

\begin{tabular}{|c|c|c|c|c|c|}
\hline \multirow{5}{*}{ 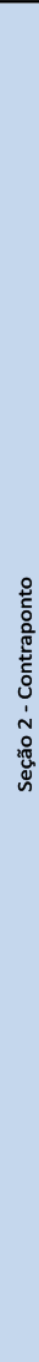 } & Parte da Seção & Objetivos & $\begin{array}{c}\text { Gêneros que compõem a parte da } \\
\text { seçăo }\end{array}$ & Sistema semiótico & Modalidades \\
\hline & Contraponto & $\begin{array}{l}\text { 1. Compreender a influência de fatores políticos, } \\
\text { ideológicos e econômicos na construção do } \\
\text { discurso científico e em sua valoração; } \\
\text { 2. Perceber a existência de "verdades" científicas } \\
\text { cotrastantes; } \\
\text { 3. Identificar discursos científicos marginais; } \\
\text { 3. Analisar e interpretar um artigo de opnião; } \\
\text { 4. Analisar os efeitos de sentido construídos pelas } \\
\text { imagens ilustrativas da parte da seção. }\end{array}$ & $\begin{array}{l}\text { * Texto introdutório ( } A \text { farsa } \\
\text { do aquecimento global) } \\
\text { * Artigo de opinião (A farsa } \\
\text { do aquecimento); } \\
\text { * Entrevista oral (Jô Soares } \\
\text { entrevista o climatologista } \\
\text { Ricardo Felicio); } \\
\text { *Verbete } \\
\text { * Glossário; } \\
\text { *Imagens ilustrativas. }\end{array}$ & $\begin{array}{l}\text { * Oral; } \\
\text { *Escrita; } \\
\text { * Visual. }\end{array}$ & $\begin{array}{l}\text { *Escrita; } \\
\text { *Imagem estática } \\
\text { (fotografias e imagens } \\
\text { computadorizadas); } \\
\text { *Imagem em movimento } \\
\text { (fotografia). }\end{array}$ \\
\hline & Atividades Seção 2 - 1 & $\begin{array}{l}\text { 1. Compreender o papel dos veículos de } \\
\text { comunicação na construção e disseminação de } \\
\text { verdades científicas; } \\
\text { 2. Analisar a orientação ideológica de um } \\
\text { determinado jornal impresso em relação ao } \\
\text { aquecimento global por meio da observação da } \\
\text { abordagem adotada para o assunto } \\
\text { (posicionamento explícito e implíito no texto, tom } \\
\text { da linguagem, escolhas lexicais, espaço destinado } \\
\text { ao assunto e sua localização no jornal); } \\
\text { 3. Contrapor discursos científicos contrastantes; } \\
\text { 4. Identificar o processo de reconstrução de } \\
\text { verdades científicas; } \\
\text { 5. Analisar e interpretar uma reportagem; }\end{array}$ & $\begin{array}{l}\text { * Questão escolar; } \\
\text { * Reportagem (0 Guru do } \\
\text { aquecimento Global); } \\
\text { * Infográfico Infográfico 4); }\end{array}$ & $\begin{array}{l}\text { *Verbal; } \\
\text { *Visual. }\end{array}$ & $\begin{array}{l}\text { *Escrita; } \\
\text { *Imagem estática } \\
\text { (fotografias e imagens } \\
\text { computadorizadas). }\end{array}$ \\
\hline & $\begin{array}{l}\text { A Grande farsa do } \\
\text { aquecimento global }\end{array}$ & $\begin{array}{l}\text { 1. Compreender a influência de fatores políticos, } \\
\text { ideológicos e econômicos na construção do } \\
\text { discurso científico e em sua valoração; } \\
\text { 2. Contrapor discursos científicos contrastantes; } \\
\text { 3. Analisar e interpretar um vídeo-documentário; } \\
\text { 4. Refletir sobre as consequências para a sociedade } \\
\text { de um discurso científico unilateral e incontestável. }\end{array}$ & \begin{tabular}{|l|} 
* Texto explicativo; \\
* Vídeo-documentário (A \\
grande farsa do aquecimento \\
global); \\
* Questão escolar.
\end{tabular} & $\begin{array}{l}\text { *Verbal; } \\
\text { *Visual. }\end{array}$ & $\begin{array}{l}\text { *Escrita; } \\
\text { *Imagem em movimento } \\
\text { (fotografia). }\end{array}$ \\
\hline & Notas & $\begin{array}{l}\text { 1. Compreender a influência de fatores políticos, } \\
\text { ideológicos e econômicos na construção do } \\
\text { discurso científico e em sua valoração; } \\
\text { 2. Refletir sobre a relação entre aquecimento global } \\
\text { e desenvolvimento sustentável. }\end{array}$ & $\begin{array}{l}\text { * Textos explicativos; } \\
\text { * Questão escolar. }\end{array}$ & $\begin{array}{l}\text { *Verbal; } \\
\text { * Visual. }\end{array}$ & $\begin{array}{l}\text { *'Escrita; } \\
\text { *Imagem estática } \\
\text { (imagem } \\
\text { computadorizada). }\end{array}$ \\
\hline \multirow{5}{*}{ 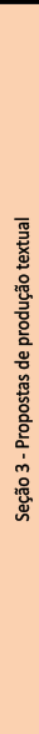 } & Parte da Seção & Objetivos & $\begin{array}{c}\text { Gêneros que compōem a parte da } \\
\text { seçāo }\end{array}$ & \begin{tabular}{|r} 
\\
\end{tabular} & Modalidades \\
\hline & A tirania de muitos & $\begin{array}{l}\text { 1. Compreender o conceito de tirania de muitos do } \\
\text { filósofo John Stuart Mill; } \\
\text { 2. Relacionar o conceito à questão do aquecimento } \\
\text { global; } \\
\text { 3. Analisar os efeitos de sentido construídos pelas } \\
\text { imagens ilustrativas da parte da seção. }\end{array}$ & $\begin{array}{l}\text { *A Artigo de opinião (A tirania } \\
\text { de muitos); }\end{array}$ & $\begin{array}{l}\text { *Verbal; } \\
\text { *Visual. }\end{array}$ & $\begin{array}{l}\text { *Escrita; } \\
\text { *Imagem estática (imagem } \\
\text { computadorizada); }\end{array}$ \\
\hline & $\begin{array}{l}\text { Proposta de produção } \\
\text { textual } 1\end{array}$ & $\begin{array}{l}\text { 1. Compreender a estrutura, situação de } \\
\text { comunicacional e intenção de comunicação do } \\
\text { gênero dissertação escolar; } \\
\text { 2. Relacionar aquecimento global, o processo de } \\
\text { construção e disseminação de verdades científicas } \\
\text { e o conceito tirania de muitos de John Stuart Mill. } \\
\text { 3. Analisar os efeitos de sentido construídos pelas } \\
\text { imagens ilustrativas da parte da seção. }\end{array}$ & $\begin{array}{l}\text { *Enunciado de proposta de } \\
\text { produção textual; } \\
\text { *Glossário. }\end{array}$ & $\begin{array}{l}\text { *Verbal; } \\
\text { *Visual. }\end{array}$ & $\begin{array}{l}\text { * Escrita; } \\
\text { *Imagem estática (imagem } \\
\text { computadorizada); }\end{array}$ \\
\hline & $\begin{array}{l}\text { Proposta de produção } \\
\text { textual } 2\end{array}$ & $\begin{array}{l}\text { 1. Compreender a estrutura, situação de } \\
\text { comunicacional e intenção de comunicação do } \\
\text { gênero carta do leitor. }\end{array}$ & $\begin{array}{l}\text { *Enunciado de proposta de } \\
\text { produção textual; } \\
\text { * Glossário. }\end{array}$ & "Verbal. & * Escrita. \\
\hline & $\begin{array}{l}\text { Proposta de produção } \\
\text { textual } 3\end{array}$ & $\begin{array}{l}\text { 1. Construir um Tumblr cujo acervo de informações } \\
\text { postadas sutente um ponto de vista específico na } \\
\text { discussão acerca do aquecimento global. }\end{array}$ & $\begin{array}{l}\text { *Enunciado de proposta de } \\
\text { produção textual; } \\
\text { * Glossário. }\end{array}$ & "Verbal. & * Escrita. \\
\hline
\end{tabular}

Tabela 3: Seção 2 e 3 do MDDI. 
A análise do LDDI a partir das tabelas descritoras revela a preocupação do material em situar seu trabalho no conceito de multiletramentos, pois é nítida a variedade gêneros que envolvem múltiplas linguagens e semioses. Além disso, busca-se caracterizar a pluralidade e diversidade cultural mediante os posicionamentos distintos que são elucidados pelas discussões promovidas ao longo das seções, tendo por base o acervo de textos selecionados.

Entretanto, nota-se, no material, a tendência a manter um trabalho individualizado junto aos alunos, seguindo o padrão já consolidado em livros didáticos, em que a participação colaborativa entre alunos na feitura das atividades, na produção textos e na construção da discussão em pauta não é valorizada. A despeito de o LDDI ter sido elaborado para rodar em tablets, há pouca motivação no próprio material para pesquisas no hipertexto e hipermídia, para curadoria de informações e para trabalho com produção de textos em gêneros multissemióticos, por exemplo, o que revela um subaproveitamento das potencialidades do dispositivo. Além disso, as propostas de atividade finais são voltadas para produção de textos em gêneros valorizados por vestibulares (dissertação e carta do leitor), embora haja uma proposta de criação de um Tumblr.

Assim, fica evidente a tendência a manter o trabalho limitado a práticas voltadas para um currículo situado em sua maioria no letramento da letra, o que dificulta o trabalho com novos letramentos, ou seja, prática situadas em novo ethos. Isso ocorre devido ao fato de o LDDI em questão ter sido produzido dentro de um sistema institucional que estipula e valoriza práticas de ensino específicas, direcionadas por um currículo fruto dessa lógica que, consequentemente, tende a reproduzir nesse material essas mesmas práticas consolidadas.

A despeito disso, é possível afirmar que o material didático em questão amplia, até certo ponto, as possibilidades de trabalho e introduz alguns elementos que possibilitam extrapolar a lógica do currículo tradicional. Exemplos disso são a predominância de texto multissemióticos no LDDI, a possibilidade de trabalhar com gêneros digitais, como aqueles que podem ser produzidos e postados em um Tumblr. Ademais, as limitações em se desvincular de práticas situadas meramente no letramento da letra podem, em parte, ser superadas de acordo com a dinâmica estabelecida para o trabalho em sala pelo professor e mediante à disponibilidade tecnológica da escola, como será elucidado na seção seguinte. Entretanto, para isso, teria um papel determinante a formação do professor para o trabalho 
com novas tecnologias e os novos e multiletramentos, além da disponibilidade de infraestrutura tecnológica na escola.

4.2 Sistema de atividades e de gêneros na implementação do LDDI

O uso do livro didático digital interativo estruturado com base na concepção de protótipo de ensino pode ampliar as possibilidades de estruturação de uma aula em função do contexto em que ela se insere e/ou dos objetivos estabelecidos. As pesquisas de Bazerman (2005) sobre conjuntos e sistemas de atividades e de gêneros e de Rojo (2007) sobre a aula como um sistema de atividades auxiliam na compreensão dessa potencialidade inerente aos protótipos de ensino.

Bazerman (2005) define o conjunto de gêneros como a coleção de gêneros que uma pessoa tende a produzir num determinado contexto e papel. O sistema de gêneros, segundo o autor, compreende os diversos conjuntos de gêneros utilizados por pessoas que trabalham juntas de uma forma organizada, além das relações padronizadas que se estabelecem na produção, circulação e uso dos textos. Por meio de um sistema de gêneros é possível capturar as sequências regulares com que um gênero segue outro gênero, dentro de um fluxo comunicativo típico de um grupo de indivíduos. Bazerman explica que o sistema de gêneros pode constituir também uma parte do sistema de atividades da sala de aula.

Rojo (2007), em análise de uma aula de história ministrada para uma turma de Ensino Fundamental, considerou a sequencialidade hierárquica que a constituía como um sistema de atividades. A partir do conceito proposto por Bazerman (2005), a autora analisou os sistemas de gêneros que compunham a aula e organizavam os textos que nela circulavam. Como resultado de sua análise, a autora concluiu que "Bazerman parece ter razão ao qualificar a aula como um sistema de atividades que convocam, cada uma delas, diferentes sistemas ou conjuntos de gêneros e textos/enunciados na sua realização" (ROJO, 2007, p. 11).

O LDDI foi estruturado de forma a comportar uma ampla gama de textos, vídeos, imagens e atividades. Assim, tendo em vista os objetivos pedagógicos gerais do material, é possível sistematizar, por meio dele, inúmeras estruturas de aula. As variedades de estruturas de aula tornam-se ainda maiores quando se considera a possibilidade de integração de navegação na internet (hipertexto e hipermídia) de forma a complementar, aprofundar e ampliar discussões possíveis dentro da temática do LDDI. A flexibilidade na estruturação de 
aulas promovidas pelo material didático digital interativo visa à adequação do trabalho a variáveis como número de aulas disponíveis, ano do Ensino Médio em que se leciona e disponibilidade ou não de conexão com internet por exemplo. Assim, é possível criar sistemas de atividades que englobem sistemas de gêneros adequados às condições disponíveis de trabalho. Ou seja, pode-se considerar que estrutura geral estabelecidas para a aula no LDDI, por meio dos objetivos para ele determinados, seja o que Rojo chamou de esqueleto do protótipo de ensino enquanto o acervo de gêneros multissemióticos preencheria esse esqueleto em função da aula pretendida e possível de se realizar.

Dependendo dos caminhos de estudo do LDDI escolhidos pelo professor ao longo da aula, o sistema de atividades e seus respectivos sistemas de gênero podem mudar. Entretanto, ao se considerar esse material como um material didático tradicional, que deva ser aplicado linearmente, da maneira como seus elementos encontram-se dispostos, haveria, então, um conjunto de atividades - e, consequentemente, possibilidades de sistemas de gêneros, limitados ao acervo nele contido.

Por outro lado, um docente formado no trabalho com novas tecnologias e novos e multiletramentos, em um contexto com disponibilidade tecnológica adequada, pode ampliar as possibilidades de implementação do LDDI. Isso ocorreria, pois, ao navegar pela internet, alunos e professor possivelmente se deparariam com infinitas possibilidades de gêneros cujas informações se relacionam à discussão. Assim, ao inserir na aula a pesquisa em tempo real e uma postura de mediação, não de mera exposição, por parte do professor, por meio do uso de dispositivos móveis e/ou computadores conectados à internet, as possibilidades de ensino se expandem e os caminhos de condução da discussão de determinado assunto, no caso da disciplina de Produção e Interpretação Textual - foco do material proposto, tornam-se imprevisíveis e, justamente por isso, ricos em razão das possibilidades de análise, verificação e contraposição de perspectivas distintas proporcionadas por meio dessa estratégia.

Nesse contexto, se um professor propusesse que os alunos construíssem parte do acervo de gêneros a ser analisado de forma colaborativa no momento da aula, por meio de pesquisa na web em tempo real, utilizando computadores, tablets e/ou celulares conectados à internet, seria possível trabalhar a habilidade de curadoria de informação e de pesquisa colaborativa. Seria possível também, após a análise em conjunto do acervo construído, propor a construção, também de forma colaborativa, de um Tumblr sobre a temática, de forma que se 
amplie e se aprofunde a questão trabalhada em aula. No Tumblr, resultado de todo trabalho feito em sala e cuja divulgação nos meios oficiais de comunicação da escola e redes sociais dos próprios alunos fora previamente determinada, poderia haver enquetes, inúmeros gêneros multissemióticos (entre eles, remixes), espaços para interação com os leitores, de forma que se incentive a participação da comunidade escolar na discussão do tema trabalhado. Nesse exemplo, a tecnologia estaria integrada à prática de sala aula, como prevê Almeida em seu conceito de web-currículo, haveria trabalho de fato com práticas de letramento - e não apenas as simulações de práticas letramentos tão comuns nas escolas -, e haveria também trabalho com multiletramentos e alguns elementos dos novos letramentos.

Dessa forma, diante da análise exposta, pode-se afirmar que parte determinante ${ }^{17}$ do trabalho adequado com protótipos de ensino a fim de se alcançar práticas situadas em novos e multiletramentos atrela-se à formação docente e à disponibilidade tecnológica.

\section{CONSIDERAÇÕES FINAIS}

Por meio desse artigo, pretendeu-se caracterizar brevemente o contexto contemporâneo permeado por novas tecnologias e analisar um material didático digital interativo voltado para o trabalho com multiletramentos e novos letramentos. A análise revelou que o LDDI construído a partir do conceito de protótipo apresenta a possibilidade de fazer com que o professor assuma um papel ativo na seleção de gêneros, escritos e/ou multissemióticos, que constituem o material, na escolha de objetivos pedagógicos a serem alcançados e os caminhos de estudo pelo LDDI ao longo de uma aula. Tais caminhos, escolhidos mediante o contexto de docência, são estruturados por meio de sistemas de atividades, que, por sua vez, estruturam sistemas de gêneros. Dependendo dos caminhos de estudo do LDDI escolhidos pelo professor ao longo da aula, o sistema de atividades e seus respectivos sistemas de gênero podem mudar. Caso se utilize, na aula, estratégias de pesquisa em tempo real por alunos em hipertexto e hipermídia, as possibilidades de gêneros que compõem os sistemas de atividade tornam-se ainda maiores e imprevisíveis. Por outro lado, se houver limitação do trabalho em sala ao acervo contido no material, podem se estabelecer práticas em que o letramento da letra predomina. 
A despeito da presença constante de multissemiose no LDDI analisado, a preocupação com o conteúdo curricular limita o trabalho com os multiletramentos e novos letramentos. Dessa forma, fica evidente que o LDDI e as novas tecnologias não são suficientes para mudar paradigmas educacionais estabelecidos, embora eles ampliem, até certo ponto, as possibilidades de ensino e introduzam alguns elementos que extrapolam a lógica do currículo tradicional. Entretanto, dentro do atual sistema educacional, os limites não podem ser ampliados a ponto de abarcarem plenamente práticas situadas em um novo ethos, pois, nesse caso, haveria uma ruptura com o sistema vigente.

\section{REFERÊNCIAS}

ALMEIDA, M. E. B. Integração currículo e tecnologias: concepção e possibilidades de criação de web-currículo. In: ALMEIDA, M. E. B.; ALVES, R. M. A.; LEMOS, S. D. V. (Org.). Web-Currículo: aprendizagem, pesquisa e conhecimento com o uso de tecnologias digitais. Rio de Janeiro: Letra Capital, 2014.

BAHKTIN, M. M. Estética da criação verbal. São Paulo: Martins Fontes, 2003[195253/1979]. Tradução de Paulo Bezerra, 4a.ed.

BAZERMAN, C. Atos de fala, gêneros textuais e sistemas de atividades: como os textos organizam atividades e pessoas In: DIONÍSIO, A.; HOFFNAGEL, J. (Orgs., Trads.) Gêneros textuais, tipificação e interação. São Paulo: Cortez Editora, 2005, p. 19-46.

BOLTER, J. D. Writing as technology. In: Writing space: Computers, hypertext and the remediation of print. Mahwah, NJ: Lawrence Erlbaum, 2002. p. 14-26.

COLL, C.; MAURI, T.; ONRUBIA, J. A incorporação das tecnologias da informação e da comunicação na educação: do projeto técnico-pedagógico às práticas de uso. In: COLL, C.; MONEREO, C. (Eds.) Psicologia da educação virtual: aprender e ensinar com as tecnologias da informação e da comunicação. Porto Alegre: Artmed, 2010, p. 66 - 93.

COPE, B.; KALANTZIS, M. Designs for social futures. In: COPE, B.; KALANTZIS, M. (Eds). Multiliteracies - Literacy Learning and the design of social futures. New York: Routledge, 2006[2000], p. 203-234.

COPE, B.; KALANTZIS, M. Multiliteracies - New Literacies, New Learning. Pedagogies: An International Journal, Vol.4, 2009, p. 164-195.

CUBAN, L. Computers meet classroom: classroom win. Teachers College Record, 1993. v. 95, n.2, p. $185-210$.

EGGS, E. Ethos aristotélico, convicção e pragmática moderna. In: AMOSSY, R. (Org.).

Imagens de si no discurso: a construção do ethos. São Paulo: Contexto, 2005.

GEE, J. P. Social Linguistics and Literacies: Ideology in discourses. London: Falmer Press, 1996. 
KALANTZIS, M.; COPE, B; HARVEY A. Assessing multiliteracy and new basics. Assessment in Education, v. 10, n. 1, p. 15-26, 2003.

KALANTZIS, M.; COPE, B. Changing the role of schools. In: B. COPE; M. KALANTZIS (Eds.). Multiliteracies - Literacy learning and the design of social futures. New York: Routledge, 2006 [2000], p. 121-148.

KRESS, G. Gains and losses: New forms of texts, knowledge, and learning. Computers and Composition, v. 22, n.1, p. 5-22, 2005.

LANKSHEAR, C.; KNOBEL, M. Sampling "the new" in new literacies. In: M. KNOBEL; C. LANKSHEAR (Eds.) A new literacies sampler: New literacies and digital epistemologies. New York: Peter Lang, 2007. Vol. 29, p. 1-24.

LEMKE J. L. Travels in Hypermodality. Visual Communication, v.1, n.3, London, 2002, p. 299-325.

LEMKE J. L. Multimedia and Discourse Analysis. In: J. P. GEE; M. HANDFORD (Eds.). Routledge Handbook of Discourse Analysis. London: Routledge, 2011. p. 263-267

LOPES, J. G. A prática docente mediada por materiais didáticos digitais interativos. 2015. 155 p. Dissertação (mestrado em Linguística Aplicada). IEL - Universidade Estadual de Campinas, Campinas, 2015.

ROJO, R. H. R. Práticas de ensino em língua materna: Interação em sala de aula ou aula como cadeia enunciativa? In: Kleiman, A; Cavalcanti, M. (Orgs.) Linguística Aplicada suas faces e interfaces. Campinas, SP: Mercado de Letras, 2007, p. 339-360.

Materiais didáticos no ensino de línguas. In: L. P. MOITA-LOPES (Org.). Linguística Aplicada na modernidade recente - Festschrift para Antonieta Celani. São Paulo, SP: Parábola Editorial/Cultura Inglesa, 2013a. p. 163-195.

Gêneros discursivos do Círculo de Bakhtin e os multiletramentos. In ROJO, R. (Org.) Escol@ conectada: Os multiletramentos e as TICs. São Paulo, SP: Parábola Editorial, 2013b, p. 13-36.

Novos multiletramentos e protótipos de ensino: Por um Web-Currículo. In: Cordeiro, G. S.; Barros, E. M. D.; Gonçalves, A. V. (Orgs.). Letramentos, objetos e instrumentos de ensino: Gêneros textuais, sequências e gestos didáticos. Campinas, SP: Pontes, 2017a, pp. 189-216.

Entre Plataformas, ODAs e Protótipos: Novos multiletramentos em tempos de WEB2. The ESPecialist: Descrição, Ensino e Aprendizagem, Vol. 38, No. 1, jan-jul 2017(b), pp. 5-25. Disponível em: https://revistas.pucsp.br/esp CThe ESPecialist. Acesso em: 14/08/2017.

SANTAELLA, L. Linguagens líquidas na era da mobilidade. São Paulo: Paulus, 2007.

SCHNEUWLY, B.; G. S. CORDEIRO \& J. DOLZ "A la recherche de l'objet enseigné: une démarche multifocale". Mimeo, inédito, 2005.

STREET, B. Literacy in theory and practice. Cambridge: Cambridge University Press, 1984. 
Revista Triângulo

ISSN 2175-1609

\section{Social literacies: critical approaches to literacy in development, ethnography and education. London: Longman, 1995.}

What's "new" in New Literacy Studies? Critical approaches to literacy in theory and practice. Current Issues. In Comparative Education. New York: Teachers College / Columbia University, v.5, n.2, 2003, p. 77-91

\section{NOTAS}

What has come to be termed the "New Literacy Studies" (NLS) (Gee, 1991; Street, 1996) represents a new tradition in considering the nature of literacy, focusing not so much on acquisition of skills, as in dominant approaches, but rather on what it means to think of literacy as a social practice (Street, 1985). This entails the recognition of multiple literacies, varying according to time and space, but also contested in relations of power. NLS, then, takes nothing for granted with respect to literacy and the social practices with which it becomes associated, problematizing what counts as literacy at any time and place and askin 'whose literacies' are dominant and whose are marginalized or resistant." (STREET, 2003, p. 77)

2 If we see literacy as "simply reading and writing" - whether in the sense of encoding and decoding print, as a tool, a set of skills, or a technology, or as some kind of psychological process-we cannot make sense of our literacy experience. Reading (or writing) is always reading something in particular with understanding. Different kinds of text require "somewhat different backgrounds and somewhat different skills" if they are to be read (i.e., read meaningfully). Moreover, particular texts can be read in different ways, contingent upon different people's experiences of practices in which these texts occur. (LANKSHEAR; KNOBEL, 2007, p. 2)

${ }^{3} \mathrm{Na}$ Retórica de Aristóteles, o termo ethos, juntamente a pathos e logos, constituem o que o filósofo clássico nomeia como as três provas engendradas do discurso, cuja função seria garantir a persuasão do ato discursivo. Eggs (2005), ao analisar o termo ethos em Aristóteles, afirma que tal conceito se relaciona a dois campos semânticos: aquele fundado na moral, em que há atitudes e virtudes, e outro relacionado a hábitos, modos, costumes e caráter. Assim, o termo ethos empregado por Lankshear e Knobel, relaciona-se ao segundo campo semântico, de forma a indicar, do ponto de vista social e cultural, o modo como um grupo atua socialmente e valora essas atuações.

4 (...) new literacies have what we call new "technical stuff”' and new "ethos stuff”. (LANKSHEAR; KNOBEL, 2007, p. 7)

5 Paradigm cases of new literacies have both new "technical stuff" (digitality) and new "ethos stuff." Peripheral cases of new literacies have new "ethos stuff" but not new "technical stuff." In other words, if a literacy does not have what we call new ethos stuff we do not regard it as a new literacy, even if it has new technical stuff. (LANKSHEAR; KNOBEL, 2007, p. 7)

${ }^{6}$ Rojo (2017a, p. 200), ao definir o termo remix, recorre ao iDicionário Aulete, no qual "remixar" significa "fazer nova mixagem de (disco, fita etc.); fazer modificação em (música já gravada), acrescentado trechos, suprimindo outros, alterando o volume de um canal etc." A autora explica que "o procedimento de alteração e mistura/hibridação originado da prática dos DJs na música, a remixagem, se estende hoje a imagens (estáticas e em movimento - vídeos), textos e todo o conjunto das outras linguagens".

${ }^{7}$ Em inglês, New London Group (NLG).

${ }^{8}$ Mídia, de acordo com a definição de Kress (2005), é um meio de circulação de mensagens culturalmente significativas.

${ }^{9}$ Ainda segundo Kress (2005), modalidade é um meio de representação baseado em uma materialidade específica, compartilhado social e culturalmente. Embora Kress, em seus estudos, adote a terminologia "modalidades de linguagem" ou "multimodalidade", o conceito de "multissemiose", preferido por Santaella (2007) e Rojo, parece-me mais pertinente para lidar com enunciados contemporâneos. Rojo (2013b, p. 22-23) explica que a semiose deriva de um sistema de signos. Já a modalidade refere-se aos diferentes modos de 


\section{Revista Triângulo}

ISSN 2175-1609

manifestação de uma semiose, às suas materialidades, como, por exemplo, o oral e a escrita nos sistemas linguísticos ou a imagem estática e em movimento na semiose visual.

${ }^{10}$ They must develop in students an ability to express and represent multilayered identity appropriate to the different lifeworlds, civic spaces, and work contexts that all citizens encounter (...). (KALANTZIS; COPE, 2006 [2000], p. 271)

11 [...] capacity to engage in collaborative politics which matches differences in relationships of complementarity [.... . (COPE; KALANTZIS, 2006 [2000], p. 272)

${ }^{12}$ They are content with being no less than actors rather than audiences, players rather than spectators, agents rather than voyeurs and users rather than readers of narrative. Not content with programmed radio, these children build their own playlists on their iPods. Not content with programmed television, they read the narratives on DVDs and Internet-streamed video at varying depth (the movie, the documentary about the making of the movie) and dip into "chapters" at will. Not content with the singular vision of sports telecasting on mass television, they choose their own angles, replays and statistical analyses on interactive digital TV.

(COPE; KALANTZIS, 2009, p. 173)

${ }^{13} \mathrm{O}$ material pode ser baixado na íntegra, em versão $\mathrm{PDF}$ (sem interatividade) ou em versão $i B o o k$ para $i P a d$, por meio do link a seguir: https://www.dropbox.com/sh/h6wfz9puu96z6i9/AADLmH-

$\underline{\text { TxQROzPSt9g4jwXMDa? } \mathrm{dl}=0}$

${ }^{14}$ Disponível em: https://itunes.apple.com/us/app/ibooks-author/id490152466?ls=1\&mt=12. Acesso em: 02/03/2017.

${ }^{15}$ Os resultados dessa pesquisa encontram-se na dissertação de mestrado de Lopes (2015).

${ }^{6}$ Tumblr é uma plataforma de blogging, também considerada uma rede social, que permite aos usuários publicarem material multimídia. A maioria dos posts feitos no Tumblr são textos curtos, mas a plataforma não chega a ser um sistema de microblog, estando em uma categoria intermediária entre os blogs de formato convencional Wordpress ou Blogger e o microblog Twitter.

${ }^{17}$ A questão das limitações do currículo vigente também são aspectos determinantes. Contudo, para a atual discussão, pretende-se exemplificar uma flexibilização possível desse currículo, sem que com ele se rompa completamente, a fim de abarcar práticas que se situem além do letramento da letra. 